\title{
Anti-biofilm activity of an exopolysaccharide from a sponge-associated strain of Bacillus licheniformis
}

\author{
SM Abu Sayem¹, Emiliano Manzo², Letizia Ciavatta², Annabella Tramice², Angela Cordone ${ }^{1}$, Anna Zanfardino ${ }^{1}$, \\ Maurilio De Felice ${ }^{1}$ and Mario Varcamonti ${ }^{*^{*}}$
}

\begin{abstract}
Background: Secondary metabolites ranging from furanone to exo-polysaccharides have been suggested to have anti-biofilm activity in various recent studies. Among these, Escherichia coli group II capsular polysaccharides were shown to inhibit biofilm formation of a wide range of organisms and more recently marine Vibrio sp. were found to secrete complex exopolysaccharides having the potential for broad-spectrum biofilm inhibition and disruption.

Results: In this study we report that a newly identified ca. $1800 \mathrm{kDa}$ polysaccharide having simple monomeric units of $\alpha$-D-galactopyranosyl-(1 $\rightarrow 2$ )-glycerol-phosphate exerts an anti-biofilm activity against a number of both pathogenic and non-pathogenic strains without bactericidal effects. This polysaccharide was extracted from a Bacillus licheniformis strain associated with the marine organism Spongia officinalis. The mechanism of action of this compound is most likely independent from quorum sensing, as its structure is unrelated to any of the so far known quorum sensing molecules. In our experiments we also found that treatment of abiotic surfaces with our polysaccharide reduced the initial adhesion and biofilm development of strains such as Escherichia coli PHL628 and Pseudomonas fluorescens.
\end{abstract}

Conclusion: The polysaccharide isolated from sponge-associated B. licheniformis has several features that provide a tool for better exploration of novel anti-biofilm compounds. Inhibiting biofilm formation of a wide range of bacteria without affecting their growth appears to represent a special feature of the polysaccharide described in this report. Further research on such surface-active compounds might help developing new classes of anti-biofilm molecules with broad spectrum activity and more in general will allow exploring of new functions for bacterial polysaccharides in the environment.

\section{Background}

Most species of bacteria prefer biofilm as the most common means of growth in the environment and this kind of bacterial socialization has recently been described as a very successful form of life on earth [1]. Although they can have considerable advantages in terms of selfprotection for the microbial community involved or to develop in situ bioremediation systems [2], biofilms have great negative impacts on the world's economy and pose serious problems to industry, marine transportation, public health and medicine due to increased resistance to antibiotics and chemical biocides, increased rates of genetic exchange, altered biodegradability and

\footnotetext{
* Correspondence: varcamon@unina.it

'Department of Structural and Functional Biology, University of Naples Federico II, Naples, Italy

Full list of author information is available at the end of the article
}

increased production of secondary metabolites [3-8]. Therefore, based on the above reasons, development of anti-biofilm strategies is of major concern.

The administration of antimicrobial agents and biocides in the local sites to some extent has been a useful approach to get rid of biofilms [9], but prolonged persistence of these compounds in the environment could induce toxicity towards non-target organisms and resistance among microorganisms within biofilms. This aspect has led to the development of more environment friendly compounds to combat with the issue. It has been found that many organisms in the marine areas maintain a clean surface. Most of the marine invertebrates have developed unique ways to combat against potential invaders, predators or other competitors [10] especially through the production of specific compounds toward biofilm-forming microorganisms [11]. Nowadays, it is
C Biomed Central

() 2011 Sayem et al; licensee BioMed Central Ltd. This is an Open Access article distributed under the terms of the Creative Commons Attribution License (http://creativecommons.org/licenses/by/2.0), which permits unrestricted use, distribution, and reproduction in any medium, provided the original work is properly cited. 
hypothesized that bioactive compounds previously thought to be produced from marine invertebrates might be produced by the associated microorganisms instead. Various natural compounds from marine bacteria, alone or in association with other invertebrates, are emerging as potential sources for novel metabolites [12] and have been screened to validate anti-biofilm activity. The quorum sensing antagonist (5Z)-4-bromo-5-(bromomethylene)-3-butyl-2(5H)-furanone (furanone) from the marine alga Delisea pulchra inhibits biofilm formation in $E$. coli without inhibiting its growth [13]. The metabolites of a marine actinomycete strain A66 inhibit biofilm formation by Vibrio in marine ecosystem [12]. Extracts from coral associated Bacillus horikoshii [14] and actinomycetes [15] inhibit biofilm formation of Streptococcus pyogenes. The exoproducts of marine Pseudoalteromonas impair biofilm formation by a wide range of pathogenic strains [16]. Most recently, exo-polysaccharides from the marine bacterium Vibrio sp. QY101 were shown to control biofilm-associated infections [17].

Compounds secreted or extracted from marine microorganisms having anti-biofilm activity range from furanone to complex polysaccharide. Although bacterial extracellular polysaccharides synthesized and secreted by a wide range of bacteria from various environments have been proven to be involved in pathogenicity [18], promotion of adherence to surfaces [19-21] and biofilm formation [22,23], recent findings suggest that some polysaccharides secreted from marine and non marine organisms also possess the ability to negatively regulate biofilm formation [17,24-27].

In this study, we show that an exo-polysaccharide purified from the culture supernatant of bacteria associated to a marine sponge (Spongia officinalis) is able to inhibit biofilm formation without affecting the growth of the tested strains. Phylogenetic analysis by $16 \mathrm{~S}$ rRNA gene sequencing identified the sponge-associated bacterium as Bacillus licheniformis. The mechanisms behind the anti-biofilm effect of the secreted exo-polysaccharide were preliminarily investigated.

\section{Results}

Bacillus licheniformis culture supernatant inhibits biofilm formation by Escherichia coli PHL628

Starting from a Spongia officinalis sample, it has been possible to distinguish, among one hundred colonies of sponge-associated bacteria, ten different kinds in terms of shape, size and pigmentation. They were screened for production of bioactive anti-biofilm metabolites. One colony for each phenotype was grown till stationary phase and the filtered cell-free supernatants obtained were used at a concentration of $3 \%(\mathrm{v} / \mathrm{v})$ against a stationary culture of the indicator strain E. coli PHL628 (Figure 1). Supernatants derived from strains SP1 and
SP3 showed a strong anti-biofilm activity (65\% and 50\% reduction, respectively). SP1 was chosen to study the nature of the biofilm inhibition mechanism. Sequencing of the 16S RNA revealed that the SP1 gene showed 99\% similarity with Bacillus licheniformis.

\section{Isolation and purification of active compounds}

The active fraction of SP1 cell free supernatant was initially found to be of polysaccharidic composition. Preliminary spectroscopic investigations indicated the presence of a compound with a simple primary structure; the ${ }^{1} \mathrm{H}$ and ${ }^{13} \mathrm{C}$ NMR spectra suggested that the polymer was composed by a regular-repeating unit; the monosaccharide was identified as an acetylated O-methyl glycoside derivative and the compositional analysis was completed by the methylation data which indicated the presence of 4-substituted galactose; in fact the sample was methylated with iodomethane, hydrolized with $2 \mathrm{M}$ triofluoroacetic acid $\left(100^{\circ} \mathrm{C}, 2 \mathrm{~h}\right)$, the carbonyl was reduced by $\mathrm{NaBD}_{4}$, acetylated with acetic anhydride and pyridine, and analyzed by GC-MS. The molecular mass of the polysaccharidic molecule was estimated to be approximately $1800 \mathrm{kDa}$ by gel filtration on a Sepharose CL6B. In TOCSY, DEPT-HSQC, and HSQC-TOCSY experiments, additional signals of a $-\mathrm{CHO}$ - and two $-\mathrm{CH}_{2}$ $\mathrm{O}$ - spin system proved the presence of not only a galactose residue but also of a glycerol residue (Gro); the relatively deshielded value for the glycerol methylene carbons at 65.6 and $65.4 \mathrm{ppm}$ was consistent with a phosphate substitution at $\mathrm{C} 1$ of glycerol. ${ }^{31} \mathrm{P}$-NMR spectrum confirms the presence of a phosphodiester group.

The position of the phosphate group between the $\alpha$-D-galactopyranosyl and the glycerol residue was unambiguously confirmed with $2 \mathrm{D}{ }^{1} \mathrm{H}{ }^{31} \mathrm{P}$-HSQC experiments. In fact, correlations between the ${ }^{31} \mathrm{P}$ resonance and H4 (3.827 ppm) of galactose were observed. This fact established the connectivity of the phosphate group to the respective carbon atoms. It follows that the repeating unit contains the phosphate diester fragment. Galactose was present as pyranose ring, as indicated by ${ }^{1} \mathrm{H}$ - and ${ }^{13} \mathrm{C}$-NMR chemical shifts and by the HMBC spectrums that showed some typical intra-residual scalar connectivities between $\mathrm{H} / \mathrm{C}$ (Table 1). The connection between galactose and glycerol into repeating unit was determined using HMBC and NOE effects. The anomeric site (99.47 and $5.071 \mathrm{ppm}$ ) of galactose presented long-range correlations with glycerol C2' (70.76 ppm) and H2' (4.120 ppm), and allowed the localization of galactose binding at C2' of glycerol. NOE contacts of anomeric proton at $5.071 \mathrm{ppm}$ with the signal at 3.839 ppm (Gro H23', table 1) confirmed this hypothesis.

Thus, the polysaccharide is composed of $\alpha$-D-galactopyranosyl-(1 $\rightarrow 2)$-glycerol-phosphate monomeric units (Figure 2). 


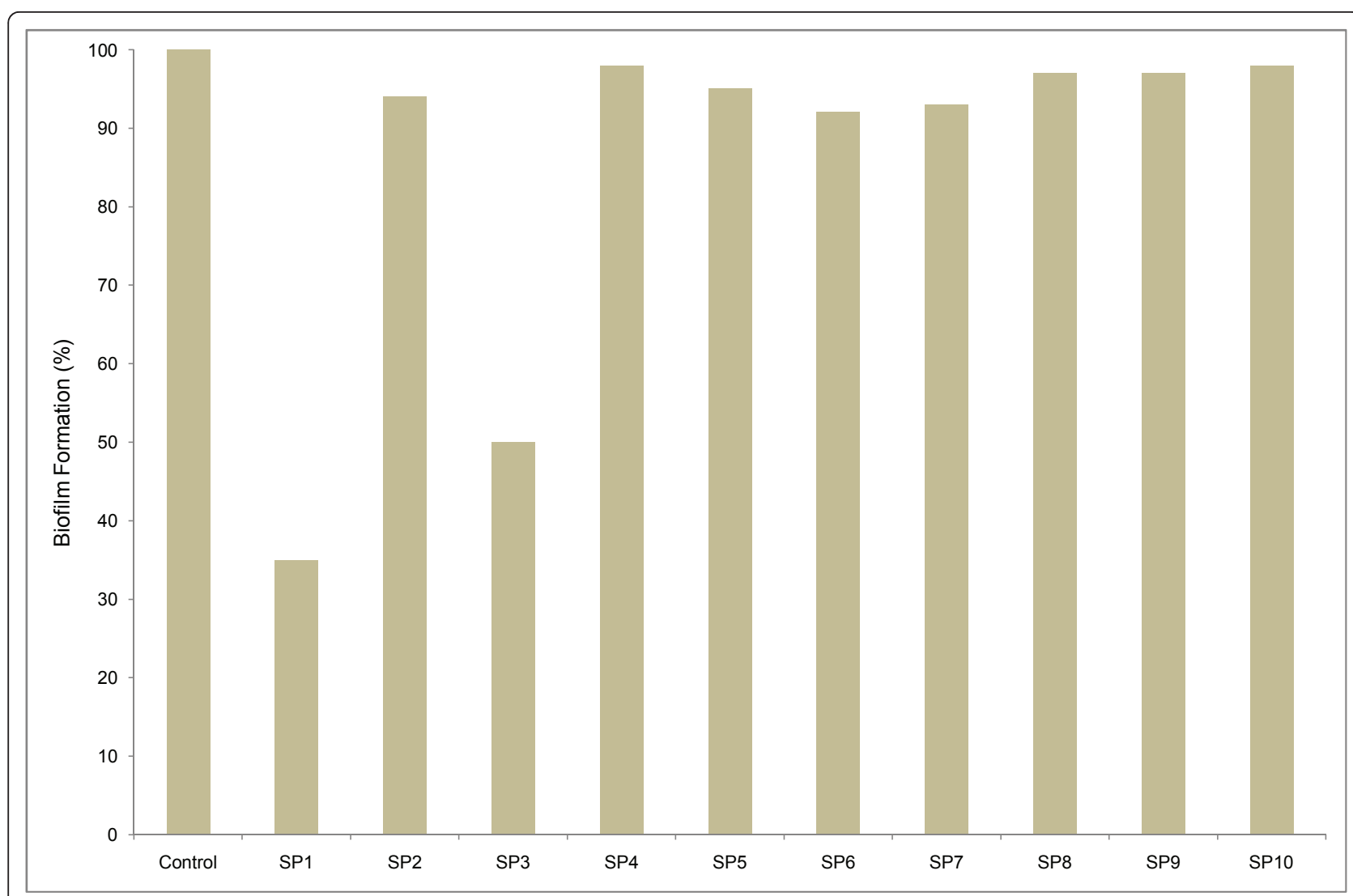

Figure 1 Anti-biofilm activity of supernatants from different strains (SP1-SP10) associated with Spongia officinalis. Biofilms of Escherichia coli PHL628 were allowed to develop in the presence of supernatants ( $3 \% \mathrm{v} / \mathrm{v})$ from marine sponge-associated isolates in 96 well microtiter well. The plate was incubated at $30^{\circ} \mathrm{C}$ for $36 \mathrm{~h}$, followed by crystal violet staining and spectrophotometric absorbance measurements $\left(\mathrm{OD}_{570}\right)$. The absorbance was used to calculate the "biofilm formation" on the $y$ axis. $\times$ axis represents cell free supernatants from different Spongia officinalis isolates. The $100 \%$ is represented by E. coli PHL628 produced biofilm.

Table $1{ }^{1} \mathrm{H},{ }^{13} \mathrm{C}$ and ${ }^{31} \mathrm{P}$ NMR chemical shift of polysaccharide(p.p.m). Spectra in $\mathrm{D}_{2} \mathrm{O}$ were measured at $27^{\circ} \mathrm{C}$ and referenced to internal sodium 3 -(trimethylsilyl)-(2,2,3,3- $\left.{ }^{2} \mathrm{H}_{4}\right)$ propionate $\left(\delta_{\mathrm{H}} 0.00\right)$, internal methanol $\left(\delta_{\mathrm{C}} 49.00\right)$ and to external aq. $85 \%(\mathrm{v} / \mathrm{v})$ phosphoric acid $\left(\delta_{\mathrm{p}} 0.00\right)$

\begin{tabular}{|c|c|c|c|c|c|c|c|}
\hline Residue & Nucleus & 1 & 2 & 3 & 4 & 5 & 6 \\
\hline \multicolumn{8}{|c|}{$\rightarrow$ 4)- $\alpha$-D-Galp-(1 $\rightarrow$} \\
\hline & ${ }^{1} \mathrm{H}$ & ${\frac{5.071}{(3.7 \mathrm{~Hz})^{\mathrm{a}}}}^{\text {HGro }}$ & 3.690 & 3.784 & $3.827^{C 6,4 \mathrm{Gal}}$ & $3.917^{C 3 G a l}$ & $3.671^{\mathrm{H} 1 \mathrm{Gal}}$ \\
\hline & ${ }^{13} \mathrm{C}$ & $99.47^{\text {H1 Gro }}$ & 69.37 & 69.95 & $\begin{array}{l}78.32^{\mathrm{H} 1 \mathrm{Gal}} \\
(7.8 \mathrm{~Hz})^{\mathrm{b}}\end{array}$ & 70.19 & $62.18^{\mathrm{H} 5 \mathrm{Gal}}$ \\
\hline \multicolumn{8}{|c|}{ Gro-1-P-(O $\rightarrow$} \\
\hline & ${ }^{1} \mathrm{H}$ & $3.865^{\text {C4Gal }}-3.906$ & $4.120^{\mathrm{C} 3,5 \mathrm{Gro}}$ & $3.839-3.770$ & & & \\
\hline & ${ }^{13} \mathrm{C}$ & $\begin{array}{l}\text { 65.63*H1Gro } \\
(4 \mathrm{~Hz})^{\mathrm{a}}-65.41^{*} \\
(4.5)^{\mathrm{a}}\end{array}$ & $\begin{array}{l}70.76^{\text {H1Gal }} \\
(7.9 \mathrm{~Hz})^{c}\end{array}$ & $\begin{array}{l}67.15 \\
(\sim 2 \mathrm{~Hz})^{d}\end{array}$ & & & \\
\hline & ${ }^{31} \mathrm{P}$ & 1.269 & & & & & \\
\hline
\end{tabular}

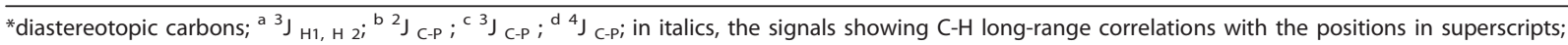
underlined are the NOE contacts with positions in superscripts. 


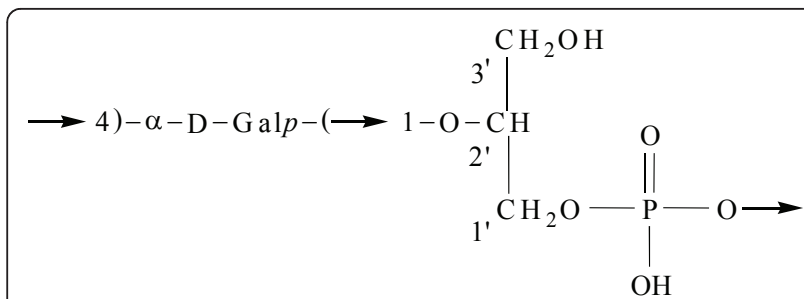

Figure $\mathbf{2}$ Repeating unit of the bacterial polysaccharide having anti-biofilm activity.

The anti-biofilm activity does not result from reducing $E$. coli and $P$. fluorescens growth

In order to check whether the anti-biofilm activity of the sponge-associated SP1 strain is dependent on the concentration used in the microtiter plate assay, the cell free supernatant from this strain was tested against biofilm formation by two organisms, E. coli PHL628 and Pseudomonas fluorescens. The results of Figure 3 clearly show that the anti-biofilm activity raises as the concentration of the supernatant increases. The anti-biofilm activity of the SP1 supernatant against the two test

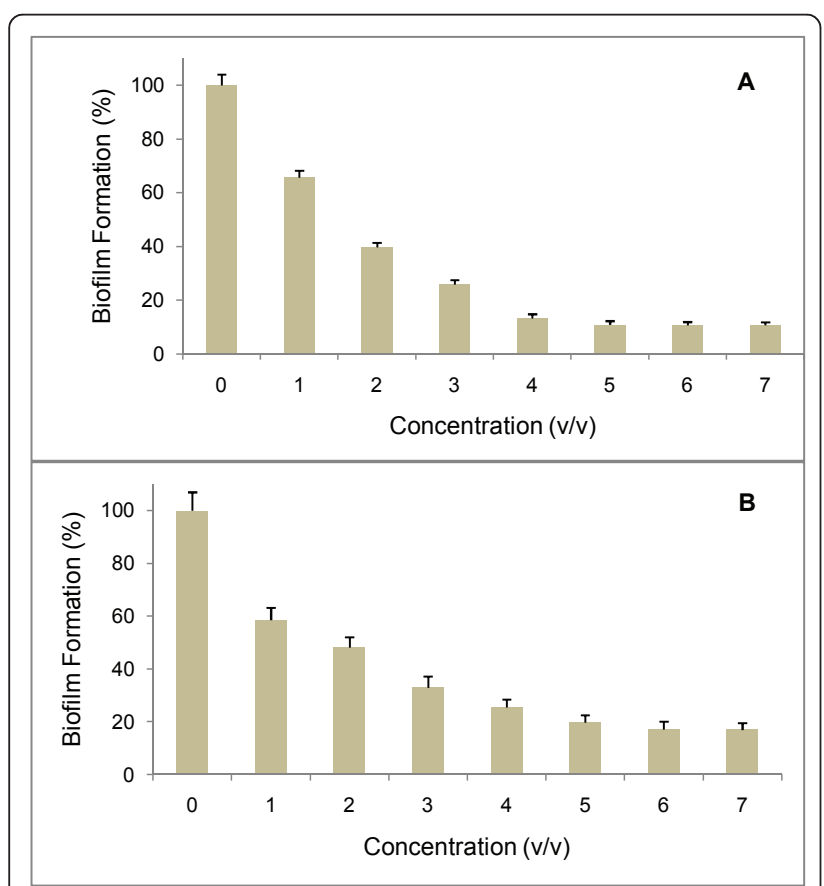

Figure 3 Anti-biofilm activity is concentration-dependent. Stationary cells of E. coli PHL628 (A) or P. fluorescens (B) were incubated along with the SP1 supernatant at different concentrations in 96-well microtiter plate. The plate was incubated at $30^{\circ} \mathrm{C}$ for $36 \mathrm{~h}$, followed by crystal violet staining and spectrophotometric absorbance measurements $\left(\mathrm{OD}_{570}\right)$. The ratio of biofilm absorbance/planktonic absorbance was calculated, and this value was used to calculate the "biofilm formation" on the $y$ axis. $x$ axis represents the concentration of supernatant used in the wells. Bars represent means \pm standard errors for six replicates. strains was comparable and perhaps slightly higher for E. coli PHL628, as in the presence of $5 \%(\mathrm{v} / \mathrm{v})$ supernatant, inhibition was about $89 \%$ and $80 \%$ on biofilm formation by E. coli PHL 628 (Figure 3A) and Pseudomonas fluorescens, respectively (Figure 3B).

To evaluate whether the anti-biofilm effect of cell-free supernatant from sponge-associated $B$. licheniformis was related to reduction of growth rate of the target strains, growth curves of both strains were measured in presence and absence of $5 \%(\mathrm{v} / \mathrm{v})$ supernatant. The resulting growth rates were found to be the same in the two conditions for both E. coli PHL628 $\left(0.51 \pm 0.02 \mathrm{~h}^{-1}\right)$ and $P$. fluorescens $\left(0.69 \pm 0.02 \mathrm{~h}^{-1}\right)$, clearly indicating that the supernatant has no bactericidal activity against the cells of biofilm-producing E. coli PHL628 or $P$. fluorescens. These data were further confirmed by the disc diffusion assay. No inhibition halo surrounding the discs was observed, thereby indicating that the supernatant has no bacteriostatic or bactericidal activity against E. coli PHL628 and P. fluorescens.

The efficiency of the sponge-associated SP1 supernatant for anti-biofilm activity was evaluated also by microscopic visualization. This approach confirmed that the inhibitory effect of the supernatant on biofilm formation increases with the increase of its concentration. Ten-fold concentrated supernatant completely inhibited biofilm formation by E. coli PHL628. Less concentrated supernatant also showed significant reduction of biofilm formation as compared to the control (Figure 4A). Very similar effects were observed with P. fluorescens (Figure 4B).

\section{Inhibitory effect of the supernatant on various strains}

To evaluate further the inhibitory effect of the SP1 supernatant on biofilm development, multiple strains regardless of pathogenicity were tested (Figure 5). Among the strains, 5 out of 10 appeared to be more than $50 \%$ inhibited in their biofilm development by the SP1 supernatant. Very interestingly, in the case of Staphylococcus aureus, the inhibition was almost $90 \%$. Among the four Bacillus species, B. amyloliquefaciens was the most affected one, whereas B. pumilis and $B$. cereus were less affected in the inhibition of biofilm development. Not a single strain was stimulated or unaffected in biofilm development by the supernatant.

\section{Preliminary characterization of the bio-active component of SP1 supernatant}

The SP1 cell free supernatant gradually loses its efficiency in decreasing biofilm formation after its pretreatment at temperatures ranging from $50^{\circ} \mathrm{C}$ to $80^{\circ} \mathrm{C}$. When the supernatant was treated at $50^{\circ} \mathrm{C}$, the inhibitory activity towards E. coli PHL628 remained 100\%, but at $60^{\circ} \mathrm{C}$ it started to decrease $(95 \%)$. Treatment at $70^{\circ} \mathrm{C}$ 

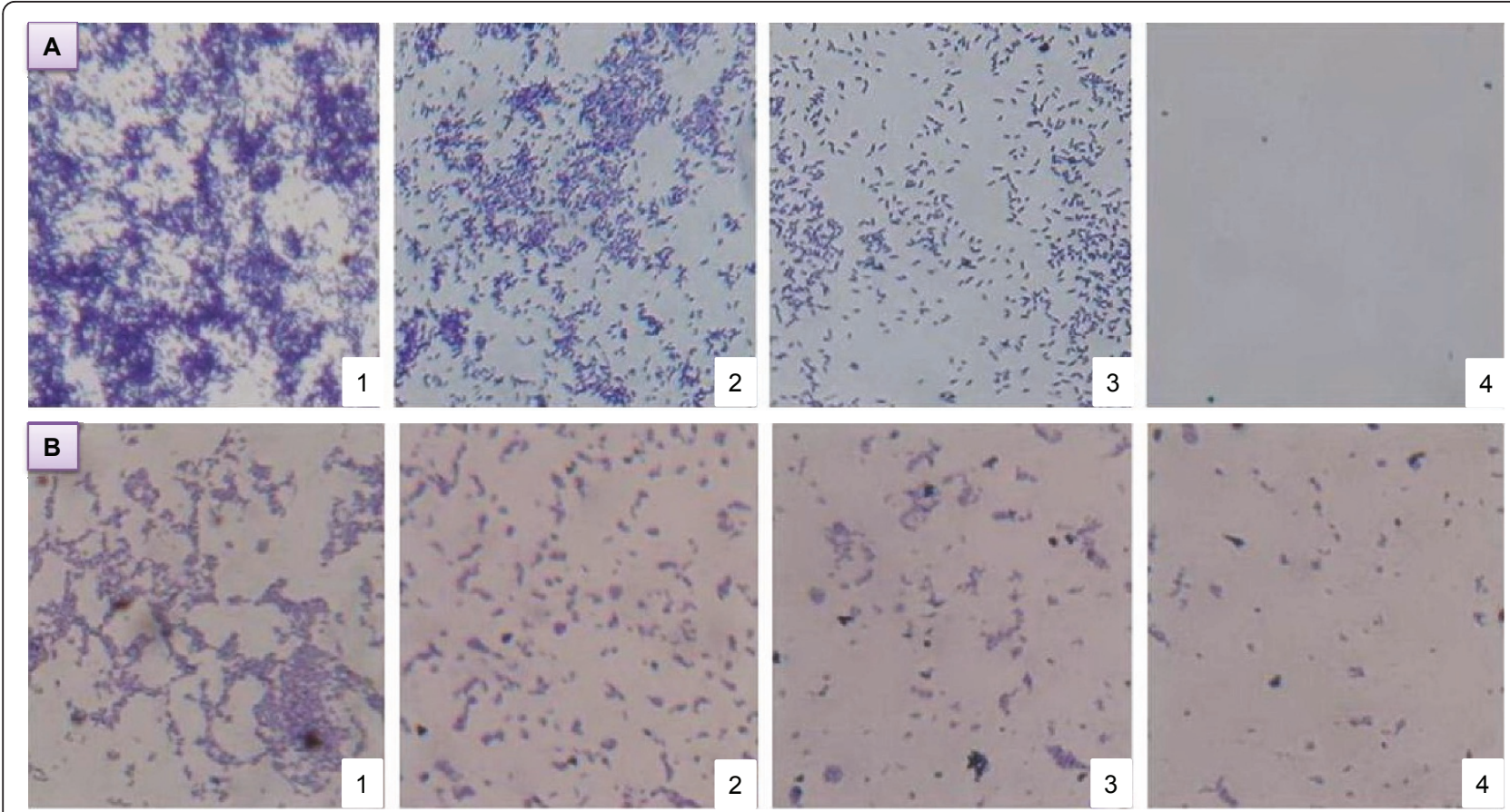

Figure 4 Microscope observation of biofilm inhibition. Biofilm inhibition of E. coli PHL628 (A) and Pseudomonas fluorescens (B) on glass cover slip under a phase-contrast microscope at a magnification of 40X. Bacterial cells were incubated with (1) 1X SP1 supernatant, (2) $2 \times$ SP1 concentrated supernatant, (3) $5 \times$ SP1 concentrated supernatant, (4) $10 \times$ SP1 concentrated supernatant. No difference in biofilm production was observed in the presence of $1 X, 2 X, 5 X$ and $10 X M^{2} 63 K_{10}$ sterile medium (not shown).

and $80^{\circ} \mathrm{C}$, resulted in $41 \%$ and $29 \%$ of the anti-biofilm activity respectively. At $90^{\circ} \mathrm{C}$ the inhibitory activity was completely lost (data not shown).

To preliminarily characterize the mechanism of action of the SP1 supernatant, this was added to bacterial cells together with the quorum sensing signals obtained from two days supernatant of an E. coli PHL628 culture in order to understand if there is a competition for the quorum sensing receptor. The use of the two supernatants together had almost the same effect on biofilm inhibition as the SP1 alone (data not shown).

To analyze whether inhibition of biofilm production is related to reduced adherence of target cells to surfaces, we tested (see Methods) the effects of SP1 supernatant on the degree of cell surface hydrophobicity of E. coli PHL628 and P. fluorescens. As shown in Figure 6, the supernatant inhibits significantly the surface hydrophobicity of $E$. coli and to a lesser extent also that of P. fluorescens.

\section{Pre-coating with SP1 supernatant inhibits initial attachment to the abiotic surface}

The polysaccharide present in the SP1 supernatant might modify the abiotic surface in such a way that there might be a reduction or inhibition of irreversible attachment of the biofilm forming bacteria to an inanimate object. We tested this hypothesis by analyzing whether there is an effect on biofilm production by E. coli PHL628 if the polystyrene wells of the microtiter plate are pre-coated with SP1 supernatant. We observed that after $36 \mathrm{~h}$, while biofilm formation was inhibited by $75 \%$ in the un-coated wells and in presence of supernatant, in the pre-coated wells the biofilm assay performed an inhibition of $92.5 \%$ (Figure 7). In addition, to evaluate further the mechanism of action in the initial attachment stage of biofilm development, the supernatant was added in the already formed biofilm. The effects were found to be much lower compared to that of the initial addition or pre-coating of the supernatant in the microtiter wells. A possible conclusion of this experiment is that the supernatant modifies the target surface in a way that prevents biofilm formation and that the initial attachment step is most important for biofilms production, at least by the organisms studied in this work.

\section{Discussion}

Marine biota is a potential source for the isolation of novel anti-biofilm compounds [12]. It has been estimated that among all the microbes isolated from marine invertebrates, especially sponge associated, Bacillus species are the most frequently found members so far [28]. Therefore the identification, in the present study, of a sponge-associated Bacillus licheniformis having anti-biofilm activity is not surprising. Our study demonstrates 


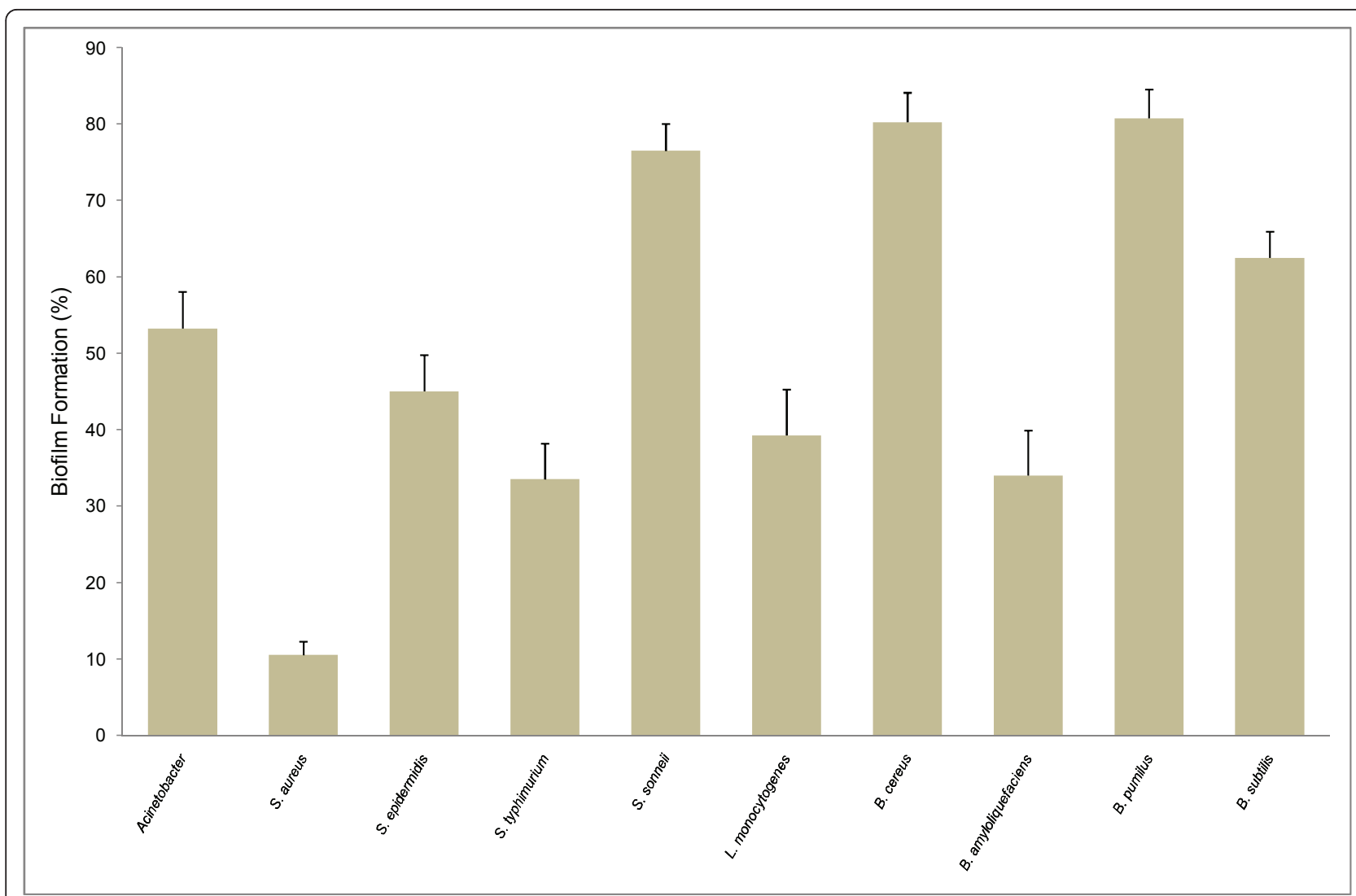

Figure 5 Inhibitory effect of the SP1 supernatant over a range of Gram-positive and Gram-negative bacteria. Biofilms of various Grampositive and Gram-negative bacteria were developed in the presence or absence of the SP1 supernatant (5\% V/V) in 96 -well microtiter plate. The plate was incubated at $30^{\circ} \mathrm{C}$ for $36 \mathrm{~h}$, followed by crystal violet staining and spectrophotometric absorbance measurements $\left(\mathrm{OD}_{570}\right)$. The ratio of biofilm absorbance/planktonic absorbance was calculated, and this value used to calculate the "biofilm formation" on the $y$ axis. The various Gram-positive and Gram-negative bacteria used in the wells are listed on $X$ axis. Bars indicate means \pm standard errors for six replicates.

the occurrence of anti-biofilm activity of a previously uncharacterized polymeric polysaccharide having monomeric structure of galactose-glycerol-phosphate. To our knowledge, no literature has ever reported the finding of such a bioactive compound from marine or other sources.

We found that the polysaccharide is secreted in the culture supernatant by the sponge-associated $B$. licheniformis and its addition to a range of Gram-positive and Gram-negative bacteria results in negative effect on their biofilm development. This broad spectrum of antibiofilm activity might help $B$. licheniformis during a competitive edge in the marine environment to establish itself on the surface of host sponges and critically influence the development of unique bacterial community.

It has been previously reported that bacterial extracellular polysaccharides can be involved both in biofilm and anti-biofilm activities. For example EPSs from $V$. cholera containing the neutral sugars glucose and galactose are important architectural components of its biofilm
[29-31]. On the other hand, EPSs from E. coli (group II capsular polysaccharide) [26], V. vulnificus (capsular polysaccharide) [32], P. aeruginosa (mainly extracellular polysaccharide) $[27,33]$ and marine bacterium Vibrio sp. QY101 (exopolysaccharide) [17] display selective or broad spectrum anti-biofilm activity. However, the potentiality of the polysaccharide described in this study over a wide range of pathogenic and non pathogenic organisms suggests that the compound might be a powerful alternative among the previously identified polysaccharides in multispecies biofilm context.

Based on the findings, we hypothesize that our polysaccharide might interfere with the cell-surface influencing cell-cell interactions, which is the pre-requisite for biofilm development [34], or with other steps of biofilm assembling. It has been reported in other cases that polysaccharides can produce anti-adherence effects between microorganisms and surfaces [35]. The E. coli group II CPS and exo-polysaccharides of marine Vibrio sp. were reported to inhibit biofilm formation not only 


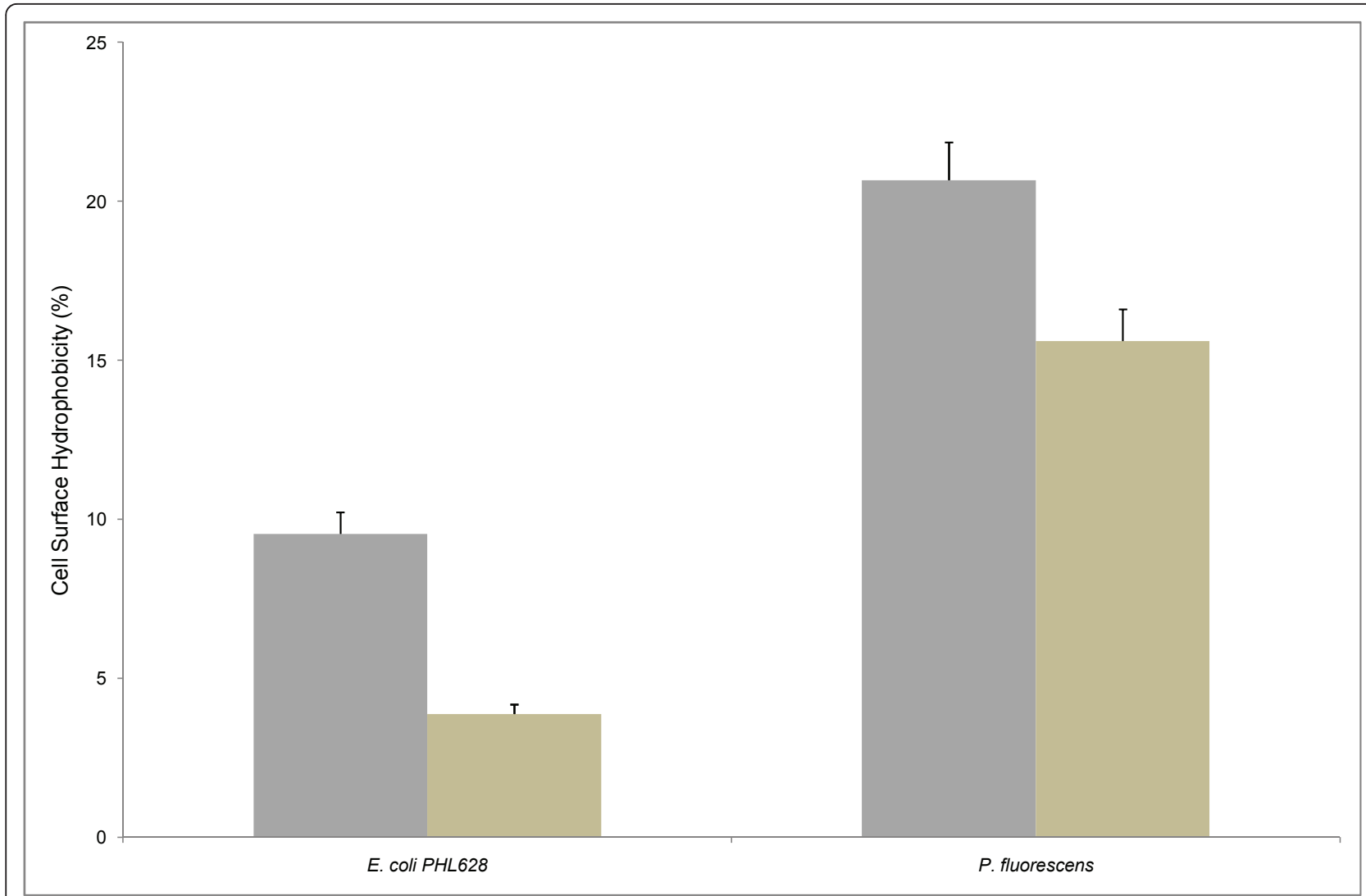

Figure 6 Cell surface hydrophobicity (CSH) assay for E. coli PHL628 and P. fluorescens. E. coli PHL628 and P. fluorescens were grown in minimal medium M63K $_{10}$ and M63, respectively, in the presence (light tan bars) and absence (gray bars) of SP1 supernatant. Bars represent means \pm standard errors for six replicates.

by weakening cell-surface contacts but also by reducing cell-cell interactions or disrupting the interactions of cell-surfaces and cell-cell [26,17]. In all the previously described polysaccharides having anti-adherence property, highly anionic nature was proposed to be the cause of interference with the adherence of cell-surface and cell-cell $[26,17,36]$. The $B$. licheniformis compound reported here has also high content of phosphate groups and thus it can be proposed that the electronegative property of the compound might modulate the surface of the tested organism in such a way that there is a reduction or complete inhibition of the attachment of cell-surface or cell-cell.

It might be possible that the compound can modify the physicochemical characteristics and the architecture of the outermost surface of biofilm forming organisms which is the phenomenon observed for some antibiotics [37]. Reduction of cell surface hydrophobicity of E. coli PHL628 and P. fluorescens clearly indicates the modification of the cell surface, resulting in reduced colonization and thereby significant contribution to anti-biofilm effect. Almost similar results were obtained with coral- associated bacterial extracts for the anti-biofilm activity against Streptococcus pyogenes [14].

Anti-biofilm effects were reported to be accompanied in most cases by a loss of cell viability or the presence of quorum sensing analogues. Interestingly, the polysaccharide in the present study is devoid of antibacterial effect, which was demonstrated by the growth curve analysis and disc diffusion test with E. coli PHL628 and P. fluorescens. An almost similar observation has been reported with the exo-polysaccharide from the marine bacterium Vibrio sp. which displayed anti-biofilm nature without decreasing bacterial viability [17]. However, further experiments suggest that the present polysaccharide enhances the planktonic growth of E. coli PHL628 in the microtiter plate wells during biofilm production (data not shown). Another interesting phenomenon of the bioactive compound reported here is the absence of competition with the quorum sensing signals presumably present in supernatants of the target biofilm-forming bacteria used in this study. In addition, none of the previously reported quorum sensing competitors is structurally related to the polysaccharide reported here. 


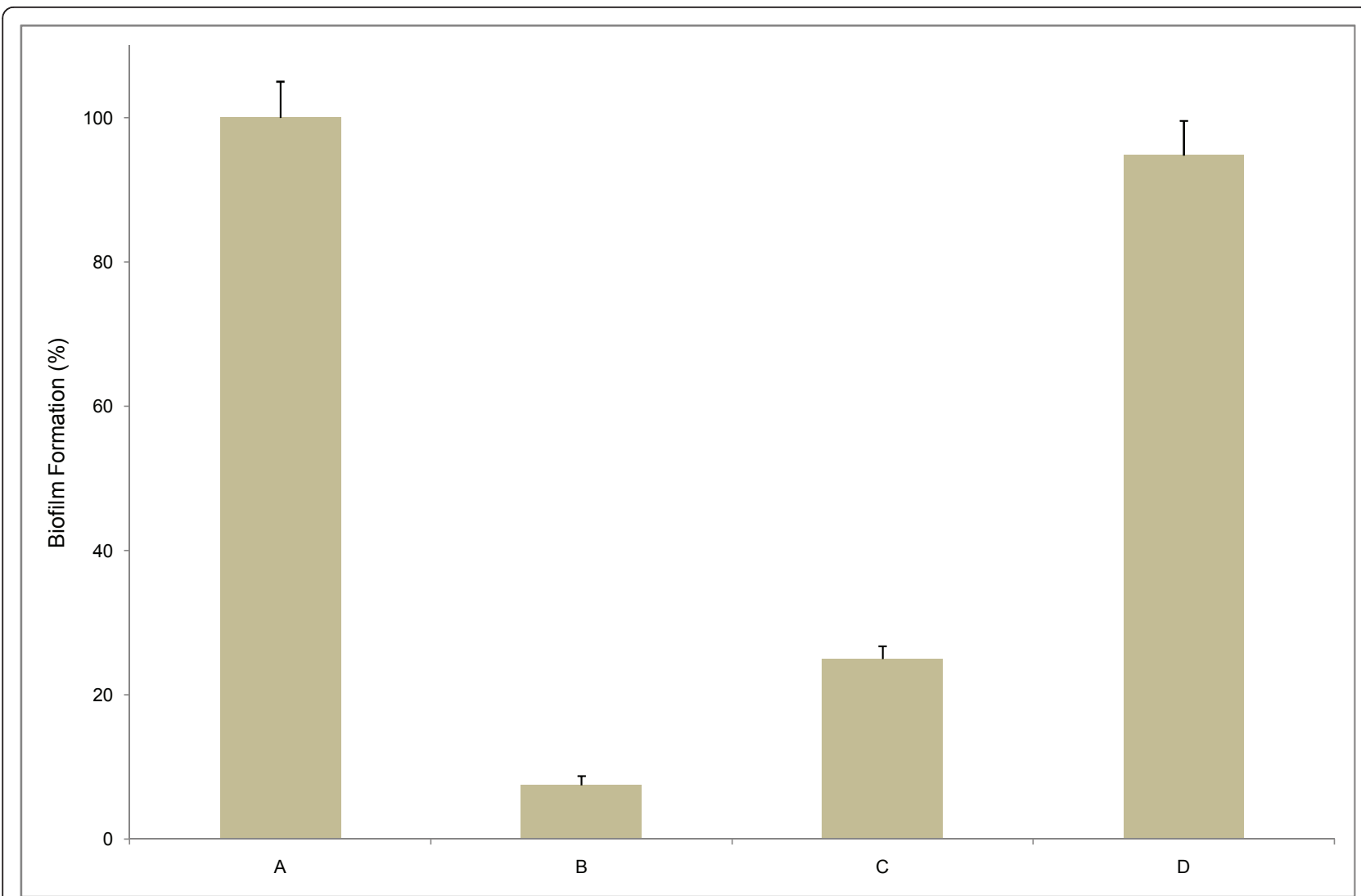

Figure 7 Pre-coating with the SP1 supernatant reduces attachment during biofilm formation. Biofilms of E. coli PHL628 were developed in 96-well microtiter plates in different conditions: no supernatant (A), wells pre-coated with supernatant (B), supernatant present (C), and supernatant added to pre-formed E. coli biofilm (D). The plate was incubated for $36 \mathrm{~h}$, followed by crystal violet staining and spectrophotometric absorbance measurements $\left(\mathrm{OD}_{570}\right)$. The ratio of biofilm absorbance/planktonic absorbance was calculated, and this value is presented as the "biofilm formation" on the $y$ axis. Bars represent means \pm standard errors for six replicates.

In the cover slip experiment, biofilm inhibition was also evidenced and displayed a gradual decrease of biofilm development with the increase of the concentration of the polysaccharide in the culture of E. coli PHL628 and P. fluorescens. In addition, pre-coating the wells of the polystyrene microtiter plate with the compound also effectively inhibits biofilm formation. To our knowledge, coating with the polysaccharide from sponge-associated bacteria for inhibition of biofilm formation has been reported for the first time here, although there are some reports on the use of pre-coating surfaces with different surfactants and enzymes [38-41].

In conclusion, the polysaccharide isolated from spongeassociated $B$. licheniformis has several features that provide a tool for better exploration of novel anti-biofilm compounds. Inhibiting biofilm formation of a wide range of bacteria without affecting their growth represents a special feature of the polysaccharide described in this report. This characteristic has already been described for other polysaccharides in a few very recent articles
[40-42]. Further research on such surface-active compounds might help developing new classes of anti-biofilm molecules with broad spectrum activity and more in general will allow to explore new functions of bacterial polysaccharides in the environment.

\section{Methods}

\section{Isolation of bacterial strains}

The bacterial strains used in this study were initially obtained from an orange-colored sponge, Spongia officinalis, collected from Mazara del Vallo (Sicilia, Italy), from a depth of $10 \mathrm{~m}$. The sponge sample was transferred soon after collection to a sterile falcon tube and transported under frozen condition to the laboratory for the isolation of associated microbes. The sponge was then mixed with sterile saline water and vortexed. A small fraction of the liquid was serially diluted up to $10^{-3}$ dilutions and then spread on plates of Tryptone Yeast agar (TY). The plates were incubated at $37^{\circ} \mathrm{C}$ for 2 days till growth of colonies was observed. Single bacterial 
colonies were isolated on the basis of distinct colony morphologies from the TY plates. Isolates were maintained on TY agar plates at $4^{\circ} \mathrm{C}$ until use.

\section{Supernatant preparation}

The isolated bacteria were sub-cultured on M63 (minimal medium) agar plates and incubated at $37^{\circ} \mathrm{C}$ for two days. A loopful of the bacterial culture from each plate was inoculated into M63 broth (in duplicate), incubated at $37^{\circ} \mathrm{C}$ for $24 \mathrm{~h}$ and then centrifuged at $7000 \times \mathrm{g}$ for 20 minutes to separate the cell pellets from the fermentation medium. The supernatants were filtered through $0.2 \mu \mathrm{m}$-pore-size Minisart filters (Sartorius, Hannover, Germany). To ensure that no cells were present in the filtrates, $100 \mu \mathrm{l}$ were spread onto TY agar plates, and $200 \mu \mathrm{l}$ were inoculated in separate wells in the microtiter plate.

\section{Screening for bioactive metabolites for biofilm inhibition}

Filtered supernatants from the marine sponge-associated isolates were used to perform the assay for biofilm formation. The method used was a modified version of that described by Djordjevic et al. [43]. Overnight cultures of E. coli PHL628 strain grown at $37^{\circ} \mathrm{C}$ in $\mathrm{M}_{63} \mathrm{~K}_{10}$ broth (M63 broth with kanamycine, $10 \mu \mathrm{g} \mathrm{ml}^{-1}$ ), were refreshed in $\mathrm{M}^{2} 3 \mathrm{~K}_{10}$ broth and incubated again at $37^{\circ} \mathrm{C}$ for 5 to $6 \mathrm{~h} .200 \mu \mathrm{l}$ of inocula were introduced in the 96 well polystyrene microtiter plate with an initial turbidity at $600 \mathrm{~nm}$ of 0.05 in presence of the filtered supernatants from the different marine sponge associated isolates. The microtiter plate was then left at $30^{\circ} \mathrm{C}$ for $36 \mathrm{~h}$ in static condition.

To correlate biofilm formation with planktonic growth in each well, the planktonic cell fraction was transferred to a new microtiter plate and the $\mathrm{OD}_{570}$ was measured using a microtiter plate reader (Multiscan Spectrum, Thermo Electron Corporation). To assay the biofilm formation, the remaining medium in the incubated microtiter plate was removed and the wells were washed five times with sterile distilled water to remove loosely associated bacteria. Plates were airdried for $45 \mathrm{~min}$ and each well was stained with $200 \mu \mathrm{l}$ of $1 \%$ crystal violet solution for $45 \mathrm{~min}$. After staining, plates were washed with sterile distilled water five times. The quantitative analysis of biofilm production was performed by adding $200 \mu \mathrm{l}$ of ethanol-acetone solution (4:1) to de-stain the wells. The level (OD) of the crystal violet present in the de-staining solution was measured at $570 \mathrm{~nm}$. Normalized biofilm was calculated by dividing the OD values of total biofilm by that of planktonic growth. Six replicate wells were made for each experimental parameter and each data point was averaged from these six.

\section{Identification and purification of anti-biofilm compound}

$144 \mathrm{ml}$ of cell free bacterial broth cultures were extensively dialyzed against water for two days, using a membrane tube of 12000-14000 cut-off; this procedure allowed us to remove the large amount of glycerol in the bacterial broth as confirmed by ${ }^{1} \mathrm{H}-{ }^{13} \mathrm{C}$-NMR experiments recorded on lyophilized broth before and after dialysis; the inner dialysate $(25 \mathrm{mg})$ was fractionated by gel filtration on Sepharose CL6B, eluting with water. Column fractions were analyzed and pooled according to the presence of saccharidic compounds, proteins and nucleic acids. Fractions were tested for carbohydrate qualitatively by spot test on TLC sprayed with $\alpha$-naphthol and quantitatively by the Dubois method [44]. Protein content was estimated grossly by spot test on TLC sprayed with ninhydrin and by reading the column fractions absorbance at $280 \mathrm{~nm}$. The active fractions were tested by the BioRad Protein System, with the bovine serum albumin as standard [45]. Finally, the presence of nucleic acids was checked by analysis of fractions absorbance at $260 \mathrm{~nm}$. Furthermore, the grouped fractions were investigated by ${ }^{1} \mathrm{H}$-NMR spectroscopy. ${ }^{1} \mathrm{H}$ and ${ }^{13} \mathrm{C}$ NMR spectra, were recorded at $600.13 \mathrm{MHz}$ on a BrukerDRX-600 spectrometer, equipped with a TCI CryoProbeTM, fitted with a gradient along the $\mathrm{Z}$-axis, whereas for ${ }^{31} \mathrm{P}$-NMR spectra a Bruker DRX-400 spectrometer was used.

The gel filtration fractions were tested for anti-biofilm activity and the active fraction resulted positive to carbohydrate tests; this latter was a homogenous polysaccharide $(6.6 \mathrm{mg})$ material. Preliminary spectroscopic investigations indicated the presence of a compound with a simple primary structure; the molecular mass of polysaccharidic molecule was estimated by gel filtration on a Sepharose CL6B which had previously been calibrated by dextrans (with a Mw from 10 to $2000 \mathrm{kDa}$ ). It's worthy to notice that some resonances in ${ }^{13} \mathrm{C}$ NMR spectrum $(78.32,70.76,65.63,67.15 \mathrm{ppm})$ were split; this suggested the presence of ${ }^{31} \mathrm{P}\left(\mathrm{J}_{\mathrm{C}-\mathrm{P}}\right.$ from 4 to $9 \mathrm{~Hz}$, see table 1 ) and its position into the polysaccharide repeating unit.

The phosphate substitution was confirmed by recording a ${ }^{31} \mathrm{P}$-NMR spectrum; it showed a single resonance at $1.269 \mathrm{ppm}$ [46].

The GC-MS analysis of the high-molecular-weight polymer was carried out on an ion-trap MS instrument in EI mode (70eV) (Thermo, Polaris Q) connected with a GC system (Thermo, GCQ) by a $5 \%$ diphenyl ( $30 \mathrm{~m} \times$ $0.25 \mathrm{~mm} \times 0.25 \mathrm{um}$ ) column using helium as gas carrier. Nuclear Overhauser enhancement spectroscopy experiments (NOESY) were acquired using a mixing time of 100 and $150 \mathrm{~ms}$. Total correlation spectroscopy experiments (TOCSY) were performed with a spinlock time of $68 \mathrm{~ms}$. 
Heteronuclear single quantum coherence (HSQC) and heteronuclear multiple bond correlation (HMBC) experiments were measured in the ${ }^{1} \mathrm{H}$-detected mode via single quantum coherence with proton decoupling in the ${ }^{13} \mathrm{C}$ domain. Experiments were carried out in the phase-sensitive mode and 50 and $83 \mathrm{~ms}$ delays were used for the evolution of long-range connectivities in the HMBC experiment. The $2 \mathrm{D}^{1} \mathrm{H}_{-}{ }^{31} \mathrm{P}$ HSQC experiment was recorded setting the coupling constants at 10 and $20 \mathrm{~Hz}$.

\section{Growth curve analysis}

The effect of the bioactive compound on the planktonic culture was checked by growth curve analysis on both E. coli PHL628 and Pseudomonas fluorescens. The supernatant of the isolate was added to a conical flask containing $50 \mathrm{ml}$ of $\mathrm{M} 63$ broth, to which a 1\% inoculum from the overnight culture was added. The flask was incubated at $37^{\circ} \mathrm{C}$. Growth medium with the addition of bacterial inoculum and without the addition of the supernatant was used as a control. OD values were recorded for up to $24 \mathrm{~h}$ at 1 -h intervals.

\section{Antibacterial activity by disk diffusion assay}

Antimicrobial activity of the supernatant was assayed by the disc diffusion susceptibility test (Clinical and Laboratory Standards Institute, 2006). The disc diffusion test was performed in Muller-Hinton agar (MHA). Overnight cultures of E. coli PHL628 and P. fluorescens were subcultured in TY broth until a turbidity of 0.5 McFarland $\left(1 \times 10^{8} \mathrm{CFU} \mathrm{ml}^{-1}\right)$ was reached. Using a sterile cotton swab, the culture was uniformly spread over the surface of the agar plate. Absorption of excess moisture was allowed to occur for 10 minutes. Then sterile discs with a diameter of $10 \mathrm{~mm}$ were placed over the swabbed plates and $50 \mu \mathrm{l}$ of the extracts were loaded on to the disc. MHA plates were then incubated at $37^{\circ} \mathrm{C}$ and the zone of inhibition was measured after $24 \mathrm{~h}$.

\section{Microscopic techniques}

For visualization of the effect of the sponge-associated bacterial supernatant against the biofilm forming $E$. coli PHL628 and Pseudomonas fluorescens, the biofilms were allowed to grow on glass pieces $(1 \times 1 \mathrm{~cm})$ placed in 6 well cell culture plate (Greiner Bio-one, Frickenhausen, Germany). The supernatant at concentrations ranging from 1 to 10 times was added in $\mathrm{M} 63 \mathrm{~K}_{10}$ (for E. coli PHL628) and M63 broth (for P. fluorescens) containing the bacterial suspension of 0.05 O.D. at $600 \mathrm{~nm}$. The wells without supernatant were used as control.

The plate was incubated for $36 \mathrm{~h}$ at $30^{\circ} \mathrm{C}$ in static condition. After incubation, each well was treated with $0.4 \%$ crystal violet for 45 minutes. Stained glass pieces were placed on slides with the bio-film pointing up and were inspected by light microscopy at magnifications of $\times 40$. Visible bio-films were documented with an attached digital camera (Nikon Eclipse Ti 100).

\section{Anti-biofilm effect on various strains and growth conditions}

Some laboratory strains such as Acinetobacter, Staphylococcus aureus, Staphylococcus epidermidis, Salmonella typhimurium, Shigella sonneii, Listeria monocytogenes, Bacillus cereus, Bacillus amyloliquefaciens, Bacillus pumilus and Bacillus subtilis were selected. All strains were grown in Tryptone Soya Broth (TSB) (Sigma) supplemented with $0.25 \%$ glucose and the same medium was used during the biofilm assay in the presence of SP1 supernatant.

\section{Competitiveness between quorum sensing factors and bioactive compounds}

For this experiment the E. coli PHL628 supernatant was prepared by using the same conditions as for that of the sponge-isolated strain. Equal volumes of the two supernatants were added either in combination or alone in the microtiter plate containing a culture of $E$. coli PHL628 at an initial turbidity of 0.05 at $600 \mathrm{~nm}$ and biofilm formation was measured as described above. Each result was an average of at least 6 replicate wells.

\section{Pre-coating of microtiter plate}

Wells were treated with $200 \mu \mathrm{l}$ of the B. licheniformis supernatant for $24 \mathrm{~h}$ and then the un-adsorbed supernatant was withdrawn from the wells. Such pre-coated wells were inoculated with E. coli PHL628 cultures having an OD of 0.05 at $600 \mathrm{~nm}$. In another set of wells that were not coated with the supernatant, the fresh culture of E. coli PHL628 having the same density mentioned above were added together with the supernatant $(5 \% \mathrm{v} / \mathrm{v})$. The microtiter plate was then incubated for 36 $\mathrm{h}$ in static conditions and biofilm formation was estimated. The control experiments were carried out in wells that were not pre-coated or initially added with the supernatant. Each result was an average of at least 6 replicate wells and three independent experiments.

In a parallel microtiter plate, the supernatant was added to the 36 -h biofilm culture in the microtiter plate and was then left at $30^{\circ} \mathrm{C}$ in static conditions for another $24 \mathrm{~h}$. The experiment was repeated six times to validate the results statistically.

\section{Microbial cell surface hydrophobicity (CSH) assay}

Hydrophobicity of the culture of E. coli PHL628 and P. fluorescens were determined by using MATH (microbial adhesion to hydrocarbons) assay as a measure of their adherence to the hydrophobic hydrocarbon (toluene) following the procedure described by Courtney et al. 
2009 [47]. Briefly, $1 \mathrm{ml}$ of bacterial culture (OD530 nm $=1.0$ ) was placed into glass tubes and $100 \mu \mathrm{l}$ of toluene along with the supernatant $(5 \% \mathrm{v} / \mathrm{v})$ was added. The mixtures were vigorously vortexed for $2 \mathrm{~min}$, incubated 10-min at room temperature to allow phase separation, then the OD530 $\mathrm{nm}$ of the lower, aqueous phase was recorded. Controls consisted of cells alone incubated with toluene. The percentage of hydrophobicity was calculated according to the formula: $\%$ hydrophobicity = [1-(OD530 $\mathrm{nm}$ after vortexing/OD530 $\mathrm{nm}$ before vortexing) $] \times 100$.

\section{Acknowledgements}

The research was supported by the Ministero dell'Istruzione dell'Università e della Ricerca (MIUR): PRIN 2008 to MV.

\section{Author details}

'Department of Structural and Functional Biology, University of Naples Federico II, Naples, Italy. ${ }^{2}$ Institute of Biomolecular chemistry, National Center for Research, Naples, Italy. ${ }^{3}$ Department of Genetic Engineering and Biotechnology, Shahjalal University of Science and Technology, Sylhet, Bangladesh.

\section{Authors' contributions}

MV planned the work that led to the manuscript; SMAS produced and analyzed the experimental data; AZ, AC and MDF participated in the interpretation of the results; MV, SMAS and MDF wrote the paper; EM, LC and AT performed the chemical characterization of the bioactive compound. All authors read and approved the final manuscript.

\section{Competing interests}

The authors declare that they have no competing interests.

Received: 13 July 2011 Accepted: 27 September 2011 Published: 27 September 2011

\section{References}

1. Flemming HC, Wingender J: The biofilm matrix. Nat Rev Microbiol 2010, 8:623-633

2. Di Lorenzo A, Varcamonti M, Parascandola P, Vignola R, Bernardi A, Sacceddu P, Sisto R, de Alteriis E: Characterization and performance of a toluene-degrading biofilm developed on pumice stones. Microbial Cell Factories 2005, 4:4

3. Mah TF, OToole GA: Mechanisms of biofilm resistance to antimicrobial agents. Trends Microbiol 2001, 9:34-39.

4. Meyer B: Approaches to prevention, removal and killing of biofilms. Inter J Biodeter Biodegrad 2003, 51:249-253.

5. Bourne DG, Høj L, Webster NS, Swan J, Hall MR: Biofilm development within a larval rearing tank of the tropical rock lobster, Panulirus ornatus. Aquaculture 2006, 260:27-38.

6. Giaouris E, Nychas GJE: The adherence of Salmonella enteritidis PT4 to stainless steel: the importance of the air-liquid interface and nutrient availability. Food Microbiol 2006, 23:747-752.

7. Anderson GG, O'Toole GA: Innate and induced resistance mechanisms of bacterial biofilms. Curr Top Microbiol Immunol 2008, 322:85-105.

8. Hoiby N, Bjarnsholt T, Givskov M, Molin S, Ciofu O: Antibiotic resistance of bacterial biofilms. Int J Antimicrob Agents 2010, 35:322-332.

9. Danese PN: Antibiofilm approaches: prevention of catheter colonization. Chem Biol 2002, 9:873-880.

10. Wahl M: Marine epibiosis. I. Fouling and antifouling: some basic aspects. Mar Ecol Prog Ser 1989, 58:175-189.

11. Selvin J, Ninawe AS, Kiran GS, Lipton AP: Sponge-microbial interactions: ecological implications and bioprospecting avenues. Crit Rev Microbiol 2010, 36:82-90.
12. You J, Xue X, Cao L, Lu X, Wang J, Zhang L, Zhou SV: Inhibition of Vibrio biofilm formation by a marine actinomycete strain A66. Appl Microbiol Biotechnol 2007, 76:1137-1144.

13. Ren D, Bedzyk LA, Ye RW, Thomas SM, Wood TK: Stationary-phase quorum-sensing signals affect autoinducer-2 and gene expression in Escherichia coli. Appl Environ Microbiol 2004, 70:2038-2043.

14. Thenmozhi R, Nithyanand P, Rathna J, Pandian SK: Antibiofilm activity of coral associated bacteria against different clinical $\mathrm{M}$ serotypes of Streptococcus pyogenes. FEMS Immunol Med Microbiol 2009, 57:284-294.

15. Nithyanand P, Thenmozhi R, Rathna J, Pandian SK: Inhibition of biofilm formation in Streptococcus pyogenes by coral associated Actinomycetes. Curr Microbiol 2010, 60:454-460.

16. Dheilly A, Soum-Soutera E, Klein GL, Bazire A, Compère C, Haras D, Dufour A: Antibiofilm activity of the marine bacterium Pseudoalteromonas sp. strain 3J6. Appl Environ Microbiol 2010, 76:3452-3461.

17. Jiang P, Li J, Han F, Duan G, Lu X, Gu Y, Yu W: Antibiofilm activity of an exopolysaccharide from marine bacterium Vibrio sp. QY101. PLOS ONE 2011, 6(4):e18514.

18. Campos MA, Vargas MA, Regueiro V, Llompart CM, Alberti S, Bengoechea JA: Capsule polysaccharide mediates bacterial resistance to antimicrobial peptides. Infect Immun 2004, 72:7107-7114.

19. Johnson MC, Bozzola JJ, Shechmeister IL, Shklair IL: Biochemical study of the relationship of extracellular glucan to adherence and cariogenicity in Streptococcus mutans and an extracellular polysaccharide mutant. $J$ Bacteriol 1977, 129:351-357.

20. Falcieri E, Vaudaux P, Huggler E, Lew D, Waldvogel F: Role of bacterial exopolymers and host factors on adherence and phagocytosis of Staphylococcus aureus in foreign body infection. I Infect Dis 1987, 155:524-531.

21. Ruas-Madiedo P, Gueimonde M, Margolles A, de los Reyes-Gavilan CG, Salminen S: Exopolysaccharides produced by probiotic strains modify the adhesion of probiotics and enteropathogens to human intestinal mucus. $J$ Food Prot 2006, 69:2011-2015.

22. Danese PN, Pratt LA, Kolter R: Exopolysaccharide production is required for development of Escherichia coli K-12 biofilm architecture. J Bacteriol 2000, 182:3593-3596.

23. Rinaudi LV, Gonzalez JE: The low-molecular-weight fraction of exopolysaccharide II from Sinorhizobium meliloti is a crucial determinant of biofilm formation. J Bacteriol 2009, 191:7216-7224.

24. Joseph LA, Wright AC: Expression of Vibrio vulnificus capsular polysaccharide inhibits biofilm formation. J Bacterio/ 2004, 186:889-893.

25. Davey ME, Duncan MJ: Enhanced biofilm formation and loss of capsule synthesis: deletion of a putative glycosyltransferase in Porphyromonas gingivalis. J Bacteriol 2006, 188:5510-5523.

26. Valle J, Da Re S, Henry N, Fontaine T, Balestrino D, Latour-Lambert P, Ghigo JM: Broad-spectrum biofilm inhibition by a secreted bacterial polysaccharide. Proc Natl Acad Sci USA 2006, 103:12558-12563.

27. Qin Z, Yang L, Qu D, Molin S, Tolker-Nielsen T: Pseudomonas aeruginosa extracellular products inhibit staphylococcal growth, and disrupt established biofilms produced by Staphylococcus epidermidis. Microbiology 2009, 155:2148-2156.

28. Kennedy J, Baker P, Piper C, Cotter PD, Walsh M, Mooij MJ, Bourke MB, Rea MC, O'Connor PM, Ross PP, Hill C, O'Gara F, Marchesi JR, Dobson AD: Isolation and analysis of bacteria with antimicrobial activities from the marine sponge Haliclona simulans collected from Irish waters. Mar Biotechnol 2009, 11:384-396.

29. Yildiz FH, Schoolnik GK: Vibrio cholerae 01 El Tor: identification of a gene cluster required for the rugose colony type, exopolysaccharide production, chlorine resistance, and biofilm formation. Proc Natl Acad Sci USA 1999, 96:4028-4033.

30. Kierek K, Watnick PI: The Vibrio cholerae 0139 O-antigen polysaccharide is essential for $\mathrm{Ca}^{2+}$-dependent biofilm development in sea water. Proc Natl Acad Sci USA 2003, 100:14357-14362.

31. Fong JC, Syed KA, Klose KE, Yildiz FH: Role of Vibrio polysaccharide (vps) genes in VPS production, biofilm formation and Vibrio cholerae pathogenesis. Microbiology 2010, 156:2757-2769.

32. Reddy GP, Hayat U, Bush CA, Morris JG Jr: Capsular polysaccharide structure of a clinical isolate of Vibrio vulnificus strain BO62316 determined by heteronuclear NMR spectroscopy and high-performance anion-exchange chromatography. Anal Biochem 1993, 214:106-115. 
33. Pihl M, Davies JR, Chavez de Paz LE, Svensater G: Differential effects of Pseudomonas aeruginosa on biofilm formation by different strains of Staphylococcus epidermidis. FEMS Immunol Med Microbiol 2010, 59:439-446.

34. OToole G, Kaplan HB, Kolter R: Biofilm formation as microbial development. Annu Rev Microbiol 2000, 54:49-79.

35. Langille S, Geesey G, Weiner R: Polysaccharide-specific probes inhibit adhesion of Hyphomonas rosenbergii strain VP-6 to hydrophilic surfaces. J Ind Microbiol Biotechnol 2000, 25:81-85.

36. Jann K, Jann B, Schmidt MA, Vann WF: Structure of the Escherichia coli K2 capsular antigen, a teichoic acid-like polymer. J Bacteriol 1980, 143:1108-1115.

37. Fonseca AP, Extremina C, Fonseca AF, Sousa JC: Effect of subinhibitory concentration of piperacillin/tazobactam on Pseudomonas aeruginosa. $J$ Med Microbiol 2004, 53:903-910.

38. Mireles JR, Toguchi A, Harshey RM: Salmonella enterica serovar typhimurium swarming mutants with altered biofilm-forming abilities: surfactin inhibits biofilm formation. J Bacteriol 2001, 183:5848-5854.

39. Kaplan JB, Chandran R, Velliyagounder K, Fine DH, Ramasubbu N: Enzymatic detachment of Staphylococcus epidermidis biofilms. Antimicrob Agents Chemother 2004, 48:2633-2636.

40. Meriem B, Evgeny V, Balashova NV, Kadouri DE, Kachlany SC, Kaplan JB: Broad-spectrum biofilm inhibition by Kingella kingae exopolysaccharide. J Bacteriol 2011, 193:3879-3886.

41. Rendueles $\mathrm{O}$, Travier L, Latour-Lambert P, Fontaine T, Magnus J, Denamur E, Ghigoa JM: Screening of Escherichia coli species biodiversity reveals new biofilm-associated antiadhesion polysaccharides. mBio 2011, 2(3): e00043-11.

42. Kim Y, Oh S, Kim SH: Released exopolysaccharide ( $r$-EPS) produced from probiotic bacteria reduce biofilm formation of enterohemorrhagic Escherichia coli 0157:H7. Biochem Biophys Res Commun 2009, 379:324-329.

43. Djordjevic D, Wiedmann M, McLandsborough LA: Microtiter plate assay for assessment of Listeria monocytogenes biofilm formation. Appl Environ Microbiol 2002, 68:2950-2958.

44. Dubois M, Gilles KA, Hamilton JK, Rebers PA, Smith F: Colorimetric methods for determination of sugars and related substances. Anal Chem 1956, 28:350-356.

45. Bradford MM: A rapid and sensitive method for the quantization of microgram quantities of protein utilizing the principle of protein-dye binding. Anal Biochem 1976, 72:248-254.

46. Rundlöf T, Weintraub A, Widmalm G: Structural studies of the enteroinvasive Escherichia coli (EIEC) O28 O-antigenic polysaccharide. Carbohydrate Research 1996, 291:127-139.

47. Courtney HS, Ofek I, Penfound T, Nizet V, Pence MA, Kreikemeyer B, Podbielbski A, Hasty DL, Dale JB: Relationship between expression of the family of $\mathrm{M}$ proteins and lipoteichoic acid to hydrophobicity and biofilm formation in Streptococcus pyogenes. PloS ONE 2009, 4:e4166.

doi:10.1186/1475-2859-10-74

Cite this article as: Sayem et al: Anti-biofilm activity of an exopolysaccharide from a sponge-associated strain of Bacillus licheniformis. Microbial Cell Factories 2011 10:74.

\section{Submit your next manuscript to BioMed Central and take full advantage of:}

- Convenient online submission

- Thorough peer review

- No space constraints or color figure charges

- Immediate publication on acceptance

- Inclusion in PubMed, CAS, Scopus and Google Scholar

- Research which is freely available for redistribution

Submit your manuscript at www.biomedcentral.com/submit
Biomed Central 